is involved, restoring functions, such as speech and ability to eat, can provide many challenges for the patient as well as the clinician.

With the increase in incidence of oropharyngeal cancers, particularly in those diagnosed as HPV positive, we are now seeing younger, more dentate patients. ${ }^{1,2}$ Patients undergoing treatment for head and neck cancer, particularly involving radiotherapy and chemotherapy, face very difficult challenges including mucositis, dry mouth, radiation caries and an increased risk of osteonecrosis of the jaws as a result of extractions. Many of these challenges are life long, and can result in complex dental treatment being required in the long term with associated considerable cost. Specialist restorative treatment is not universally available within the NHS in England.

We would like to share with you the specialist restorative oncology service delivered to all head and neck cancer patients at Torbay Hospital, South Devon. All patients receive a preoperative oral screen by the restorative oncology team, and a full and ongoing treatment plan is made. Necessary treatment, prior to cancer treatment, is carried out within the department, and advice on oral care is given to help patients through their cancer treatment. In addition, after cancer treatment, patients receive continuing restorative care and regular hygienist care at no charge. We feel this puts head and neck cancer patients in line with the support received by patients suffering from other types of cancer. This service is of significant benefit to all head and neck cancer patients. With the evolvement of new commissioning, this issue needs to be discussed and understood.

Our newly launched website, www. mouthcareincancer.co.uk has been designed to provide information for head and neck cancer patients, healthcare professionals and patients undergoing chemotherapy for other cancers.

We would welcome feedback from other head and neck cancer specialist centres regarding their services and experiences in the hope that we can improve the care for these patients across the country.

C. Drysdale, A. Green, Torquay
1. Curado M, Hashibe M. Recent changes in the epidemiology of head and neck cancer. Curr Opin Oncol 2009; 21: 194-200.

2. Lajer C B, von Buchwald C. The role of human papillomavirus in head and neck cancer. APMIS 2010; 118: 510-519.

DOI: 10.1038/sj.bdj.2013.691

\section{VENDING MACHINE THREAT}

Sir, the use of vending machines is becoming popular in developing countries such as India and China. ${ }^{1}$ Their use is increasingly found in school premises, where the income from them can be used to supplement limited budgets. ${ }^{2}$ The problem is accessibility; students can walk from their classroom and use one coin to obtain a whole range of sugary snacks and carbonated drinks. Young children enjoy this freedom, yet the machines offer them some of the most unhealthy food options and increase snacking frequency during school hours. Indeed, most studies show that the use of school vending machines is positively correlated with confectionery consumption and negatively correlated with fruit consumption. ${ }^{3}$ Evidence from developed countries shows significant differences in the caries level of children from schools with and without vending machines. ${ }^{4}$

While some schools in some countries are trying to implement rules and programmes that eliminate these unhealthy options, it is often difficult and expensive to offer fresh fruits and vegetables as an alternative. ${ }^{5}$ However, according to the Centre for Science in the Public Interest (CSPI), schools that have switched to selling healthier foods in vending machines have not experienced a reduction in vending machine revenue. ${ }^{6}$

Developed countries have learnt this lesson and adopted a public health approach by developing guidelines and/ or legislation about the appointment of bodies responsible for the management of vending machines in school (eg US Department of Agriculture) and what should be loaded in the machines. ${ }^{6}$ Developing countries should not delay in adopting these positive lessons.

\section{Masood, Y. Masood, Malaysia}

\section{J. T. Newton, London}

1. Euromonitor International. Vending in emerging countries. Market Research World, 17 May 2013. Available at: www.marketresearchworld.net/ content/view/157/77/

2. Damle S G. Fill it, shut it, and forget it...!!! J Indian Soc Pedod Prev Dent 2008; 26: 4.

3. Kubik M Y, Lytle L A, Hannan P J, Perry C L,
Story M. The association of the school food environment with dietary behaviors of young adolescents. Am J Public Health 2003; 93: 1168-1173.

4. Maliderou M, Reeves S, Noble C. The effect of social demographic factors, snack consumption and vending machine use on oral health of children living in London. Br Dent J 2006; 201: 441-444, 437.

5. American Academy on Pediatric Dentistry Council on Clinical Affairs. Policy on vending machines in schools. Pediatr Dent 2008; 30(7 Suppl): 49-50.

6. Center for Science in the Public Interest. School Vending Machines "Dispensing Junk". Washington: Center for Science in the Public Interest, 2004. Available at: http://www.cspinet.org/ new/200405111.html (accessed 13 April 2013).

DOI: 10.1038/sj.bdj.692

\section{CEMENT-INDUCED TRISMUS}

Sir, a paediatric patient was referred to our A\&tE department from their GDP for trismus. The 8-year-old patient had attended the dentist two days earlier for occlusal fillings on both his 26 and 36. Immediately on leaving the dental surgery the patient and parent noticed that the young child could not open his mouth and was locked in position. Concerned, they re-attended the dental surgery, and on examination the dentist could not decipher the cause of the trismus and urgently referred the child to the maxillofacial A\&tE department. The dentist had used two ID blocks to anesthetise the patient.

On examination in ActE there was no facial asymmetry, swelling or bruising which would indicate any potential trauma caused by an ID block resulting in possible trismus. Furthermore, the mouth opening was less than $1 \mathrm{~mm}$, and this was an unusual acute finding with no extraoral or intraoral signs of swelling. The patient was in no pain, and was quite astonished that the filling had been that 'strong'. This idea of the filling being 'strong' led to further questioning. The child reported that on placement of both the upper and lower filling he had been asked to bite down hard. Nothing was placed in between the teeth when biting down, and the patient left the surgery still biting down. Following this the patient could not open his jaw.

Using a Mitchell's trimmer the contact points between the 26 and 36 were broken. Immediate resolution of the trismus was achieved.

I believe this may be the first case of glass-ionomer cement induced trismus reported in the scientific literature!

M. Basati, by email

DOI: 10.1038/sj.bdj.2013.693 